\title{
O FUNDO MARINHO DA BAÍA DA ILHA GRANDE, RJ: O RELEVO SUBMARINO E A SEDIMENTAÇÃO NO CANAL CENTRAL
}

\author{
Wellington Ceccopieri Belo,' Gilberto T. M. Dias ${ }^{2}$ e Marcelo Sperle Dias ${ }^{3}$ \\ Recebido em 13 nov., 2001 / Aceito em 20 jun., 2003 \\ Received Nov. 13, 2001 / Accepted Jun. 20, 2003
}

\begin{abstract}
Based on high-resolution seismic data (sub-bottom profiler 7,0 kHz and side scan sonar $100 \mathrm{kHz}$ ) and geological bottom samples, interesting aspects of the llha Grande bay seabed were investigated. The seabed along the eastern-central channel of the bay was characterized by eight bottom sedimentary patterns. Such patterns showed variations in the texture, in the bio-debris content and in the acoustic back-scattering of the sediments. Among these patterns, lithobioclastic muds are closer to the land, terrigenous muds are closer to Itha Grande and sands are far eastward from the central channel. Sediment analyses indicated a low energy environment predominantly in the lithobioclastic muds area, subject to some random events of higher energy. It seems to influence the area by selecting the bottom sediments, besides the submarine topography. Observed evidences of modern facies transitions from sub-environments dominated by higher energy agents (waves) to facies dominated by lower energy agents (tides, bottom currents) were related to the complex submarine topography and to the coast line orientation. The boundary geometry among the ecofacies also suggests a hydrodynamic control by wave action and bottom currents. Evidences of these combined effects of waves and currents may be approached in a future study, based on the observed bedforms.

The observed characteristics of the eastern-central channel seabed of the bay indicate that oscillations on the level of energy may be acting on the sediments sorting. Therefore regularity of the seabed has an important role in relation to the sediment environment on the Itha Grande bay central channel.
\end{abstract}

Keywords: high resolution seismic; sediments; bathymetry; ecofacies; Ilha Grande bay.

\section{RESUMO}

Aspectos interessantes do relevo submarino e da sedimentação na baía da Itha Grande foram investigados com base em sísmica de alta resolução (perfilador de 7,0kHz e sonar de varredura lateral $100 \mathrm{kHz}$ ), e amostras de sedimentos. 0 fundo marinho na região centro-leste do canal central da baía pode ser caracterizado por oito padrões sedimentares superficiais de fundo (ecofácies), que refletem variaçōes na textura, no teor de biodetritos e no caráter acústico dos sedimentos. A disposição dos contatos entre as ecofácies sugere que existam padrões dominados por agentes de maior energia, e padrões dominados por agentes de menor energia, relacionadas à topografia submarina e à orientação da linha de costa. Ecofácies areno-lamosas (tipos transitórios) estão associadas a estruturas sedimentares (formas de fundo) obtidas nos registros de sonar. Tais estruturas estão localizadas em profundidades em torno de 16m, próximo a Conceição de Jacaré, onde ocorre uma transição textural de leste para oeste de um padrãa de fundo grosso para um padrão fino. É possivel que a ação de forçantes oceanográficos sobre as ecofácies, contribuam para 0 entendimento da sedimentação na baía. Assim, as feições observadas (faciológicas e morfodinâmicas) do fundo marinho, sugerem que oscilações no nível de energia do meio, podem estar determinando o selecionamento dos sedimentos e caracterizando diferentes tipos de fundo.

Palavras-chave. sísmica de alta resoluușão; sedimentos; batimetria; ecofácies; baía da llha Grande.

\footnotetext{
Centro de Pesquisas Leopoldo A. Miguez de Mello - CENPES - PETROBRAS, Ilha do Fundão, Cidade Universitária, Q7 s/n, Rio de Janeiro, RJ, 21949-900, 3865-6848, wceccopieri@petrobras.com.br

2 Laboratório de Geologia Marinha - LAGEMAR - UFF, Av. Litorânea, s/n, Gragoatá, Niterói, RJ, 2629-5930, Gilberto@igeo.uff.br

3 Laboratório de Oceanografia Geológica - LOG - UERJ, R. S. Francisco Xavier, 524, Rio de Janeiro, RJ, 2587-7722, sperle@ueri.br
} 


\section{INTRODUÇÃO}

A baía da llha Grande está localizada entre os meridianos $44^{\circ} \mathrm{W}$ e $44^{\circ} 40^{\prime} \mathrm{W}$ e entre as latitudes $23^{\circ} \mathrm{Se} 23^{\circ} 40^{\prime} \mathrm{S}$, compondo um sistema estuarino com a baía de Sepetiba. Está inserida numa área relativamente bem preservada e é considerada uma região importante onde ocorrem remanescentes da floresta atlântica insular. Possui uma significativa diversidade de ecossistemas marinhos, sendo em grande parte rodeada por costões rochosos, ilhas, praias arenosas e manguezais, características marcantes da costa verde do sudeste Brasileiro, onde a Serra do Mar intercepta 0 litoral em diversos pontos. Na região do canal central da baía (Figura 1), constata-se que sua geomorfologia é bastante heterogênea. Os processos físicos de circulação e sedimentação atuantes no canal podem apresentar flutuações e resultar em selecionamento dos sedimentos de fundo, em função da geometria da baía. 0 presente trabalho endereça estas questões, integrando informações geológicas e geofísicas na área centro-leste do canal central. 0 estudo investiga e caracteriza a distribuição das ecofácies nesta região. Constatações importantes acerca da ocorrência de diferentes padrões sedimentares de fundo, em função da geomorfologia submarina são abordadas.

\section{Topografia submarina}

0 entendimento de feiç̃̃es do relevo submarino da baía recebeu importante contribuição com o trabalho de Dias e outros (1990), no qual, a partir da interpretação de uma compilação de 30 folhas de bordo da Diretoria de Hidrografia e Navegação (DHN) os autores apresentaram o primeiro mapa batimétrico de detal he da baía da llha Grande, analógico, na escala de 1:80000 e com resolução de 1,0m. Neste mapa, algumas feições notáveis da morfologia submarina são observadas, tais como os canais fluviais submersos, oriundos de períodos de nível de mar mais baixo (Figura 1), e uma depressão costeira entre a llha Grande e 0 continente (canal central) com profundidade de $55 \mathrm{~m}$. Em geral, as maiores profundidades estão no lado oeste do canal central (20 a 30m), enquanto no lado leste do mesmo, estas variam entre 10 e $25 \mathrm{~m}$.

Dois canais dragados também são observados: 0 canal de acesso do TEBIG-Petrobras no lado oeste, de orientação NE-SW e profundidade média de 25m; e, no lado leste, o canal de acesso ao Porto de Sepetiba, dragado a $24 \mathrm{~m}$ e de orientação NW-SE. Ambos permitem a navegabilidade de embarcações de grande calado (cargueiros e petroleiros). Na plataforma interna, adjacente à baía, as profundidades

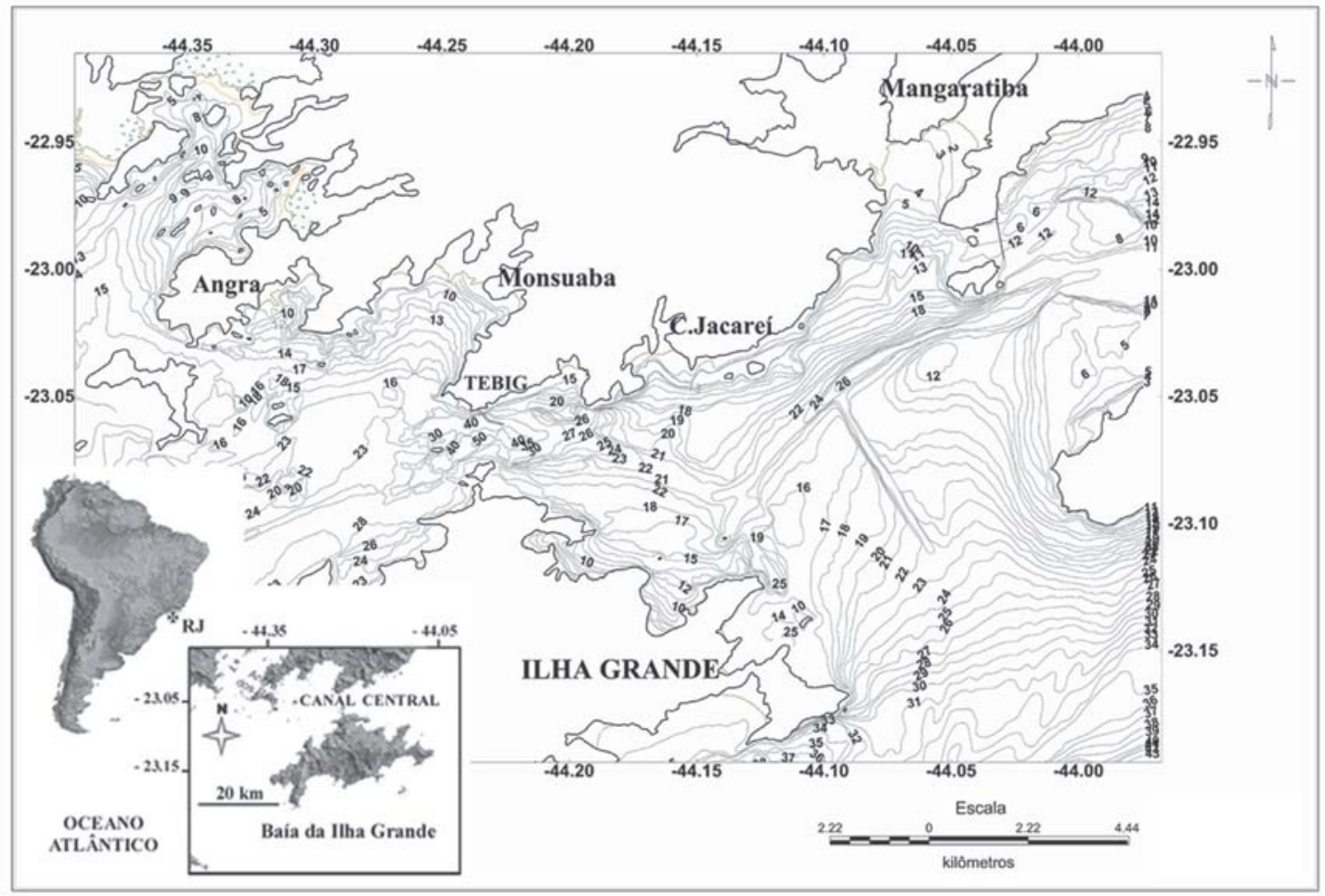

Figura 1 - Área de trabalho. Localização da baía da Ilha Grande e sua batimetria heterogênea. Intervalo de contorno de 1,0m. Modificado de Dias et. al. (1990).

Figure I - Study area. Location of Ilha Grande Bay. Bathymetric contour interval is $1 \mathrm{~m}$. Modified from Dias et. al (1990). 
estão em torno de 40m, com um suave gradiente de 1:900 $(0,001 \mathrm{~m} /$ $\mathrm{m})$, acentuando-se nas proximidades do maciço cristalino da Ilha Grande alcançando 1:50 (0,02m/m) (DIAS; PEREIRA; DIAS, 1990).

\section{Características sedimentares}

0 trabalho pioneiro de Mahiques (1987), com base em 153 amostras de fundo, obteve o primeiro traçado da textura de fundo da baía da Ilha Grande, e também da distribuição percentual de biodetritos carbonáticos, de selecionamento dos grãos e do teor de argila. Posteriormente, Dias e outros (1990), utilizando dados sedimentológicos de amostras superficiais oriundas de vários trabalhos pretéritos, inclusive de Mahiques (1987), apresentaram um mapa textural da baía, na escala de 1:80000. A partir desses mapas pode-se identificar que areias grossas e médias estão na face leste da baía e na plataforma interna até a isóbata de 50m, areias muito finas e finas na face oeste da baía e amplamente distribuídas na plataforma interna, e lamas em regiões de mais baixa energia, no canal central e em enseadas abrigadas. Outras características interessantes na área estudada também foram relatadas nestes trabalhos pioneiros: a) ocorrência de pelotas de lama associadas à fração grossa, a leste da região do canal central; b) a baixa maturidade mineralógica; c) presença de fragmentos de bioclastos retrabalhados em ambiente de mais alta energia, concentrados a uma profundidade de $20 \mathrm{~m}$; e d) ocorrência de carapaças de foraminíferos de origem recente. Estas são feições comuns nesta região, assim como sedimentos bioclásticos, relíquias com teores de carbonato de cálcio que predominam entre 10 e 25\% (CORRÊAA et al., 1997).

\section{Estudos integrados}

Apesar de se ter algum conhecimento sobre os sedimentos superficiais de fundo, diferentes ferramentas de investigação do fundo marinho como, por exemplo, a sísmica de alta resolução associada à sedimentologia, ainda não haviam sido empregadas conjuntamente na baía. Este modelo tem sido amplamente aplicado no estudo de ambientes sedimentares, principalmente em águas rasas (FURTADO, 1995; BAPTISTA NETO; SILVA; FIGUEIREDO, 1996; BORGELD et al., 1999; GOFF et al., 1990). Esta integração permite relacionar quantitativamente características dos registros acústicos diretamente às propriedades dos sedimentos sondados. Dessa forma, pode-se ter uma melhor compreensão da variabilidade regional dos sedimentos de fundo e dos processos de deposição atuantes.

Pode-se diferenciar quantitativamente 0 tipo de eco-caráter registrado no perfilador de subfundo em função da litologia predominante, do grau de compactação sedimentar, do arranjo interno das estruturas e das camadas sedimentares em subsuperfície (DAMUTH, 1975; DAMUTH; HAYES, 1977). Os registros sísmicos destes tipos de eco-caráter auxiliam no entendimento de processos sedimentares, com base em interpretações das feições do sinal acústico traduzido por sua cor em escala de cinza e seu padrão regional de distribuição.

De modo complementar, padrões de reflexão de imageamento sonográfico são ideais para o reconhecimento de feições submarinas e de mudanças no padrão sedimentar superficial de fundo. A partir de variações no sinal acústico refletido pela superfície do fundo marinho, em função de variações batimétricas e texturais, esses tipos de ecocaráter colaboram para a identificação de áreas de maior mobilidade de sedimentos de fundo, e de afloramentos rochosos (FISH; CARR, 1990; JUNG et al.., 1998).

A utilização integrada de dados geofísicos de alta resolução tem propiciado importantes aplicaçóes na indústria de petróleo durante as fases de exploração e produção, identificando obstáculos e feições geológicas de interesse e fornecendo subsídios para estudos geotécnicos (PIAUILINO; MALDONADO; CASTANÕS, 1999). Essa integração é favorecida ainda quando combinados a parâmetros geológicos amostrados in situ, e interpretados à luz de parâmetros oceanográficos observados na região.

\section{MATERIAL E MÉTODOS}

Foi utilizado o seguinte conjunto de dados na realização deste trabalho (Figura 2):

- Dados sedimentológicos do Mapa Geológico / Geomorfológico da baía da Itha Grande (DIAS; PEREIRA; DIAS, 1990), na escala 7:80000, com base nas amostras superficiais de sedimentos existentes de campanhas pretéritas;

- Dados batimétricos analógicos também do Mapa Geológico/ Geomorfológico da baía da Ilha Grande (DIAS; PEREIRA; DIAS, 1990), na escala 1:80000, com intervalo de contorno de 1,0m;

- Dados geofísicos de sísmica rasa (ecobatimetria, perfilador de 3,5$7,0 \mathrm{kHz}$ e sonar de varredura lateral 100kHz) obtidos em campanhas de campo;

- Dados sedimentológicos superficiais de fundo coletados em campanha de campo, em locais espećficicos a fim de se confirmar os padrões geofísicos do eco.

\section{Dados geológicos}

Os dados geológicos pretéritos são provenientes de 153 amostras sedimentológicas de Mahiques (1987), classificados de acordo com Dias (1996), e um mapa de Dias e outros (1990) que mostra prováveis 


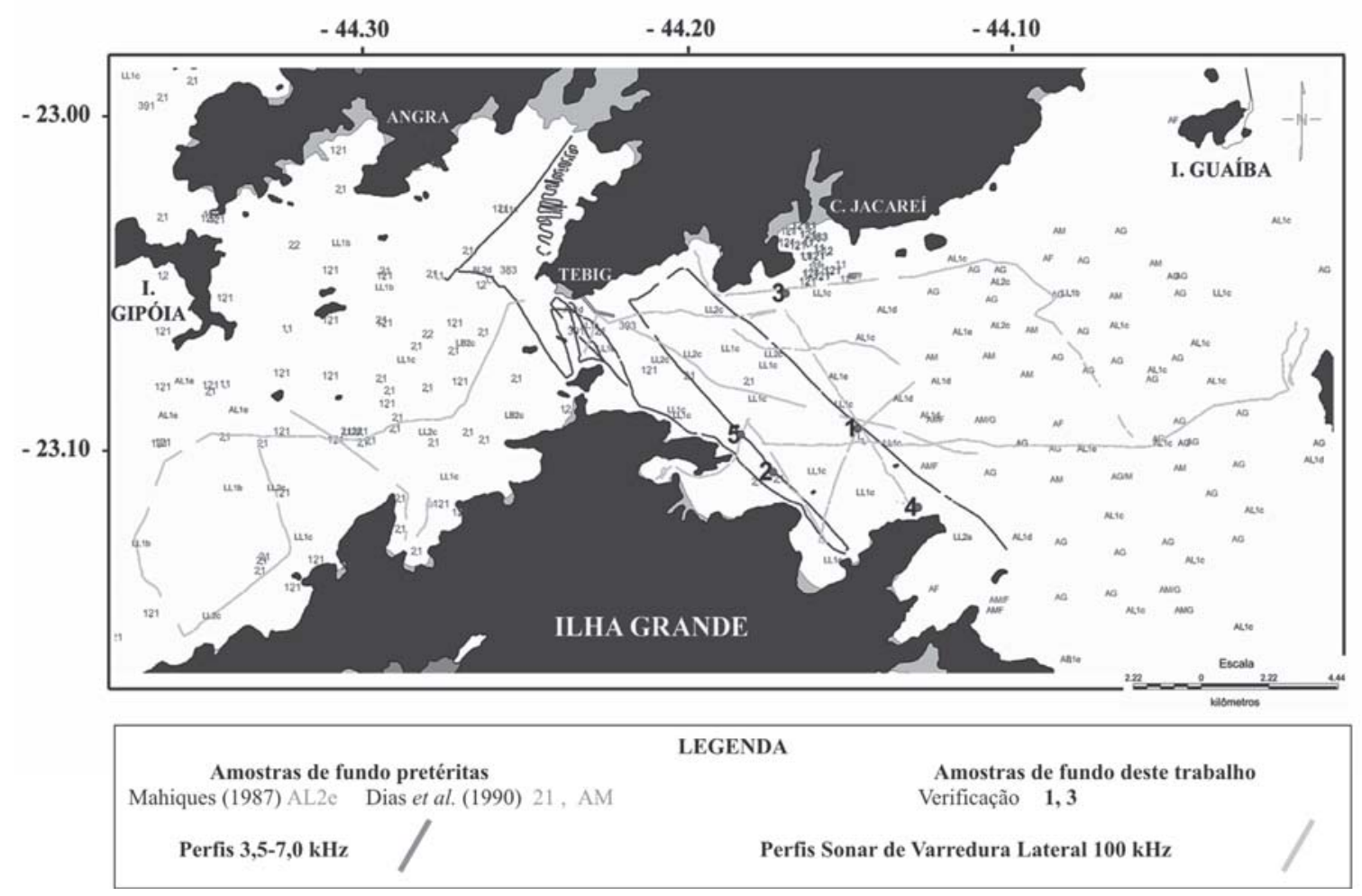

Figura 2 - Mapa base de dados geofísicos e geológicos.

Figure 2 - Location of geological (bottom-sediment superficial samples) and geophysical dato

(3.5 and $7 \mathrm{kHz}$ sub-bottom echo-sounder and side scan sonar, $100 \mathrm{kHz}$, images).

transições texturais. Esses mapas foram utilizados no planejamento das linhas geofísicas.

Foram coletadas adicionalmente amostras sedimentares de verificação em alguns locais onde se julgou necessário maior definição geológica, confrontando-as com as amostras pretéritas. Estas amostras de verificação foram coletadas com um amostrador tipo van-Veen sobre as linhas de levantamento geofísico do sonar e do perfilador, onde seus traçados se cruzaram. A análise granulométrica foi realizada através de peneiramento da fração grossa e pipetagem da fração fina de acordo com Suguio (1973), em duplicata, com e sem eliminação do carbonato de cálcio com ácido clorídrico (30\%) presente nas amostras, a fim de se verificar onde a fração biodetrítica carbonática seria mais importante. 0 teor de matéria orgânica foi obtido com base no uso de peróxido de hidrogênio (10\%). A classificação comparativa foi feita de acordo com Shepard \& Moore (1954) e Larsonneur e outros (1982).

0 mapa analógico batimétrico da baía, de Dias e outros (1990), foi digitalizado e transformado em arquivos ASC II. Usando o programa Oasis Montai, v. 4.3 da Geosoft Inc, este gride foi reprocessado e reduzido à área de interesse do estudo no canal central onde, inicialmente, foi realizada uma krigagem com tamanho de célula de $55 \mathrm{~m}$ e distância de branqueamento de $180 \mathrm{~m}$. Procedeu-se uma segunda gridagem, por mínima curvatura, mascarando-se 0 gride, onde foi utilizado o tamanho de célula de 45m (Figura 3).

\section{Dados geofísicos}

Os dados geofísicos foram obtidos por ecossondagens contínuas, posicionados com DGPS. Foram 156,32km de linhas de imageamento do fundo submarino com sonar de varredura lateral (EG \& G - 260, $100 \mathrm{kHz}$ ), e 78,67km em perfilagens de subfundo (Raytheon RTT 1000 A - PTR 7,0kHz) nos primeiros 10 - $15 \mathrm{~m}$ de camada sedimentar, realizados em três campanhas (maio e dezembro de 1999 e setembro de 2000). Com base nos registros geofísicos, foram identificados os tipos de eco-caráter superficial observados com 0 perfilador e os padrões de reflexão do sonar. Os dados geofíisicos são correlacionados nos pontos onde os respectivos traçados se cruzam (Figura 2), e ainda com as informações de amostras dos sedimentos superficiais nesse ponto de cruzamento. A combinação dessas informações permitiv a caracterização dos padrões sedimentares de fundo (ecofácies).

\section{RESULTADOS E DISCUSSÃO}




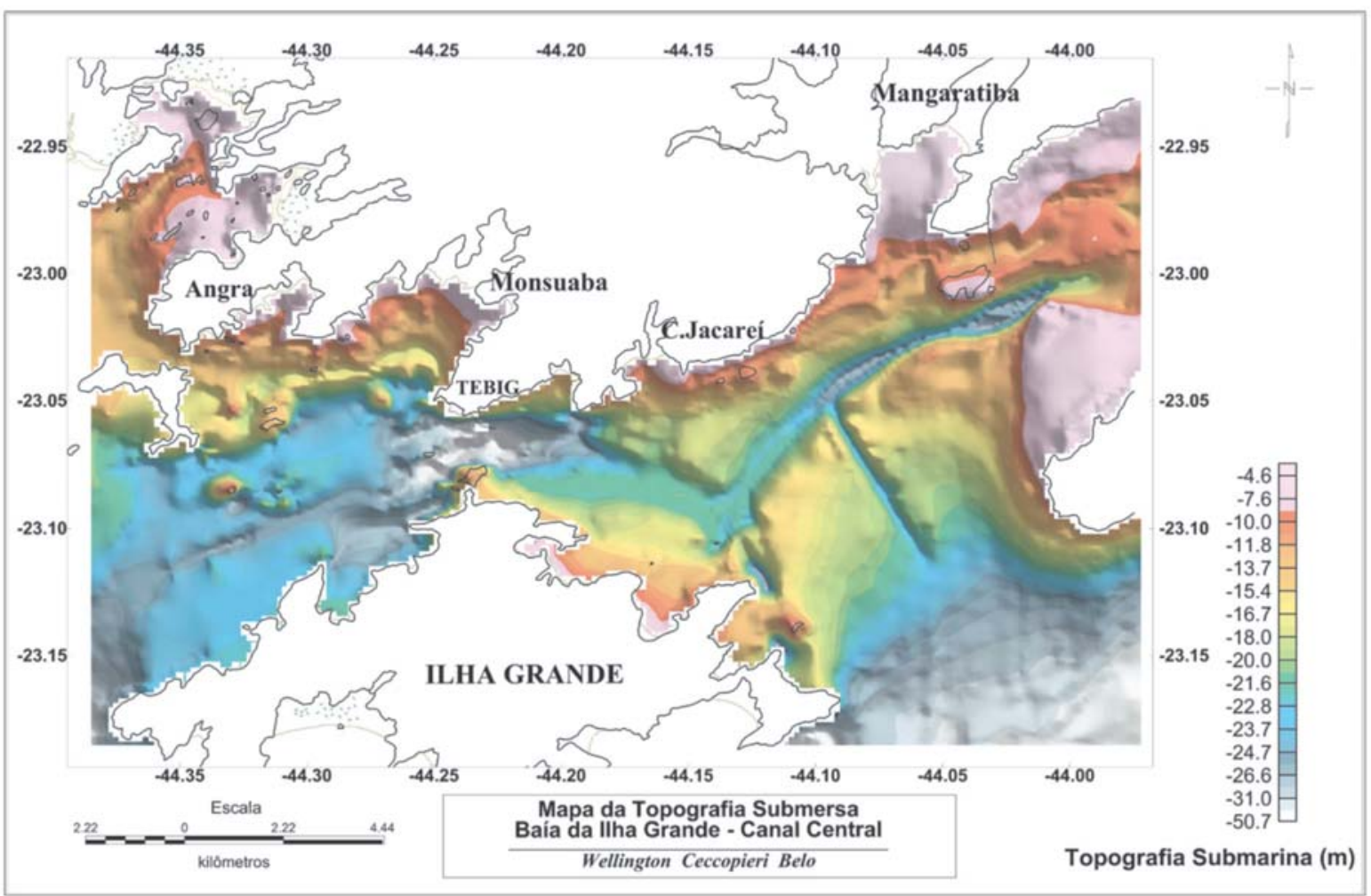

Figura 3 - Mapa batimétrico digital da região do canal central da baía da Ilha Grande. Tamanho de célula 45m e intervalo de contorno 3m. Métodos de gridagem utilizados: kriging e mínima curvatura (mascarado). Re-processamento do gride original do mapa batimétrico de Dias et. al. (1990).

Figure 3 - Bathymetry of the Ilha Grande Bay central channel. Grid cell interval is $45 \mathrm{~m}$ and contour interval is $3 \mathrm{~m}$.

Neste trabalho, dados geofísicos e dados sedimentológicos foram analisados de forma integrada, no qual foram identificados padrões de eco-caráter de sísmica rasa (perfilador de subfundo e de sonar de varredura lateral), e observadas formas de fundo associadas a alguns destes padrões. A seguir são apresentados os padrões sedimentares superficiais do fundo submarino do setor centro-leste da baía da llha Grande, e algumas considerações sobre a atuação de forçantes oceanográficos na distribuição da ocorrência destes padrões, em relação a características da geomorfologia da baía.

\section{Tipos de eco-caráter}

A partir da análise dos registros do perfilador de subfundo $7,0 \mathrm{kHz}$, foram observados sete tipos de eco-caráter superficiais. A distribuição destes padrões acústicos pode ser visualizada na Figura 4, painel superior (mapa de eco-caráter 7,0kHz). Constatou-se que os tipos de eco-caráter em que há melhor definição dos refletores e penetração do sinal (tipos
5, 6 e 7) estão mais próximos da llha Grande e de regiões abrigadas, tais como enseadas. Também foram observados de forma mais isolada na região mais central da área de estudo. Os tipos em que não houve penetração do sinal (tipos 1 e 2) ocorreram próximo do TEBIG. Os tipos 3 e 4 ocorreram de forma isolada, intercalados com os tipos anteriormente descritos.

Com base no padrão de reflexão obtido nos registros de sonar de varredura lateral, visualizado na Figura 4, painel inferior (mapa de ecocaráter sonar $100 \mathrm{kHz}$ ), foram observados quatro tipos de eco-caráter. Os padrões de reflexão foram classificados de acordo com sua intensidade e textura nos registros. 0 padrão mais forte e de "textura grossa", foi classificado como "cinza escuro", o padrão mais claro e de "textura fina" foi classificado como "cinza claro". Os padrões intermediários foram classificados em função desses dois exemplos extremos. Também foram observados al guns locais com características de transição bastante gradual entre dois padrões distintos, e que foram classificados como "faixa de transição". Em geral, os padrões mais "escuros" localizaram-se mais a 

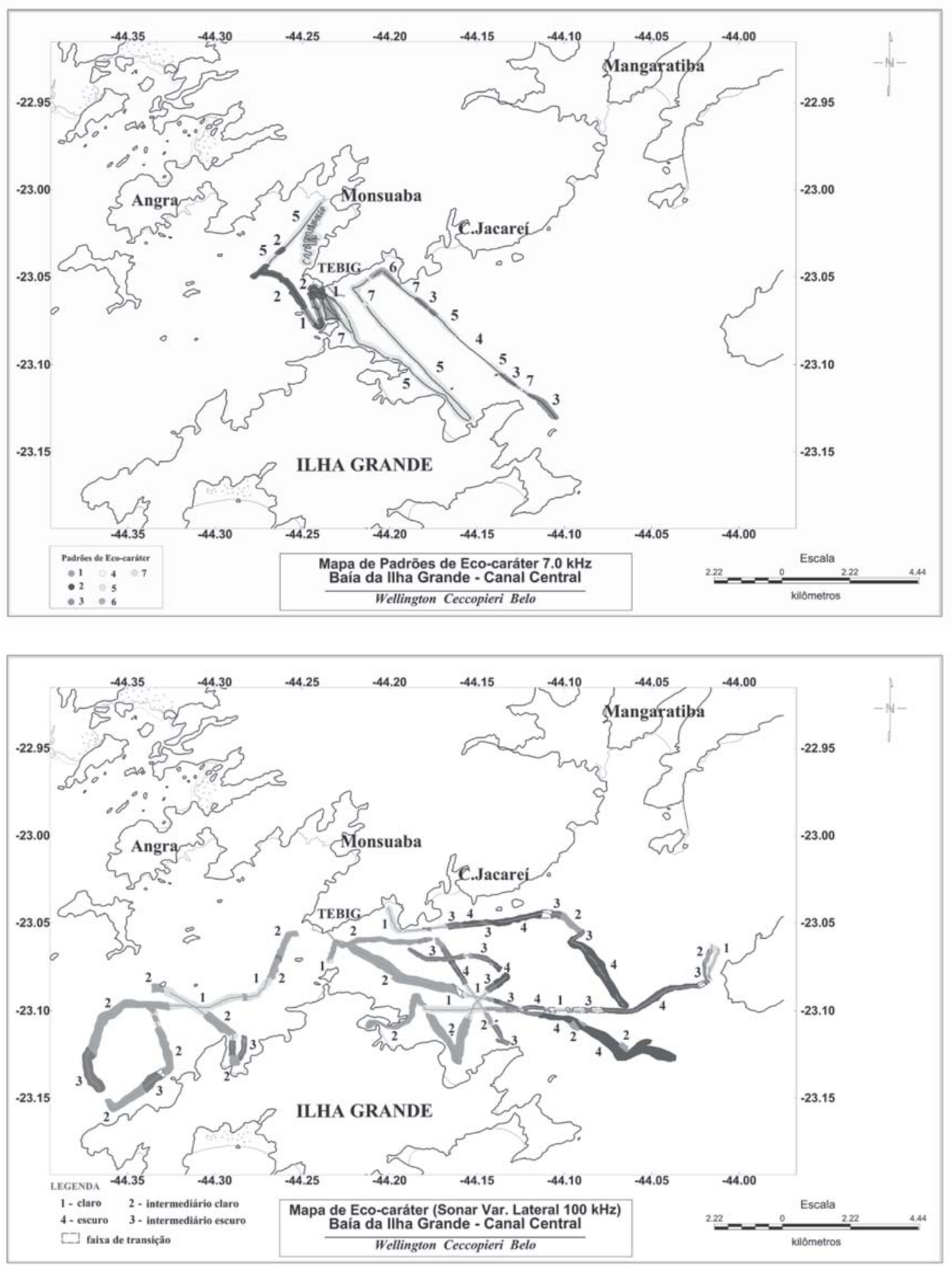

Figura 4 - Mapas de eco-caráter superficial da região do canal central da baía da Ilha Grande, com base em registros de perfilador de subfundo $7 \mathrm{kHz}$ (painel superior) e de sonar de varredura lateral $100 \mathrm{kHz}$ (painel inferior).

Figure 4 - Echo-character distribution on the Ilha Grande Bay central channel. Upper panel based on 7 kHz sub-bottom profiler data and lower panel based on side scan sonar (100 kHz) images. 
leste, os padrões mais "claros" ocorreram na região mais central e em áreas abrigadas.

\section{Características e distribuição regional das ecofácies}

Foram estabelecidos esquemas ilustrativos (Figura 5) associados a cores, que reúnem informaçōes geofísicas e geológicas caracterizando as ecofácies da região do canal central da baía da llha Grande (Figura 6). Os tipos de padrões acústicos (do perfilador e do sonar) foram

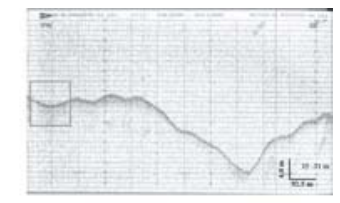

(a)

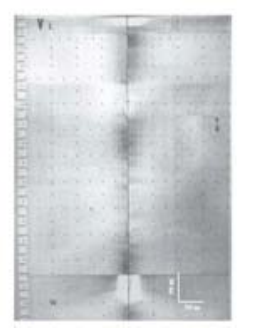

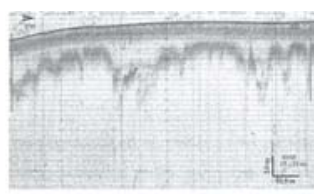

(b)

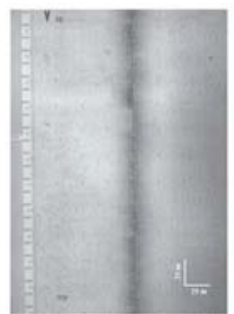

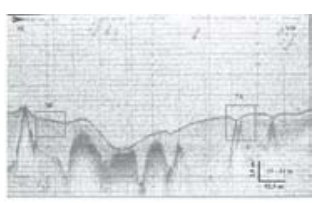

(c)

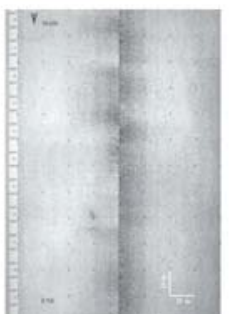

Figura 5 - Exemplos de esquemas utilizados para a caracterização dos padrões sedimentares de fundo (ecofácies) da porção centro-leste do canal central da baía de llha Grande - RJ. Painel (A) Ecofácies II - Área litobioclástica média; Painel (B) Ecofácies V - Lama terrígena; Painel (C) Ecofácies VII - Marga arenosa. Figure 5 - Examples of bottom echo-facies on the central-eastern portion of the Ilha Grande Bay central channel - RJ. (A) Echo-facies I/ - Litho-bioclastic medium sand; (B) Echo-facies V - Terrigenous mud; (C) Echo-facies VII - Sandy maerl.

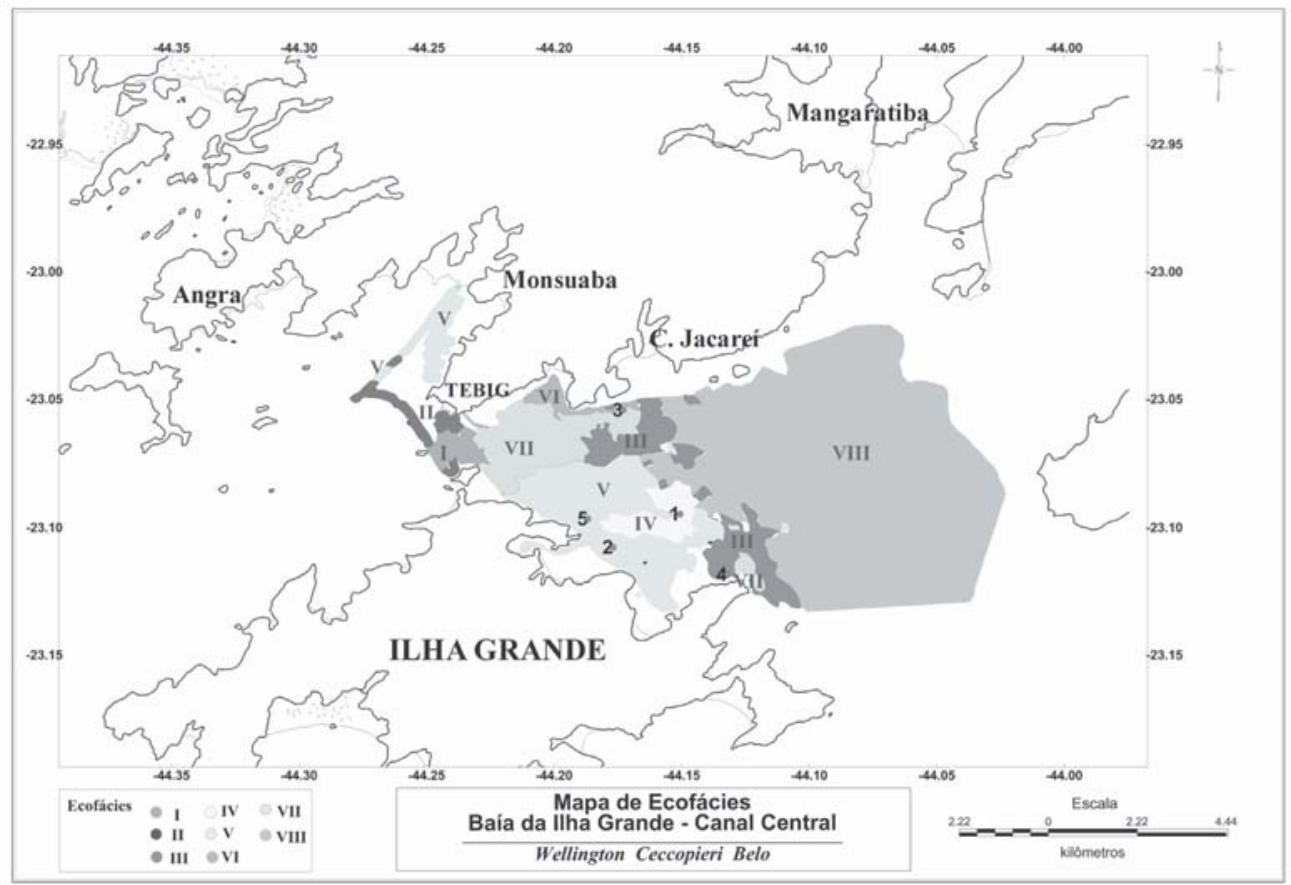

Figura 6 - Ecofácies da porção centro-leste do canal central da baía da llha Grande: (I) - Lama terrígena;

(II) - Areia litobioclástica média; (III) - Areia litobioclástica muito fina; (IV) - Lama terrígena arenosa; (V) - Lama terrígena; (VI) - Marga arenosa; (VII) - Marga arenosa; (VIII) - Areia litoclástica média a grossa.

Figure 6 - Echo-facies distribution on the central-eastern portion of the Ilha Grande Bay central channel. (I) Terrigenous mud; (VI) Sandy maerl; (VII) Sandy maerl; (VIII) Coarse to medium litho-clastic sand. 
associados com amostras geológicas de fundo pretéritas existentes na área de sobreposição das linhas geofísicas (área quadrada): perfilador $7,0 \mathrm{kHz}$ - na parte superior, e sonar de varredura lateral $100 \mathrm{kHz}$ - na parte inferior.

Foi observado que ecofácies mais arenosas, as quais ocorrem na porção leste, com teores não-significativos de $\mathrm{CaCO}_{3}$ e de finos associados a gradientes batimétricos suaves a moderados, em profundidades em torno de 15 a 20m, vão sendo substituídas, em direção à depressão costeira do canal central, por ecofácies mais lamosas com maior teor relativo de finos e de biodetritos $\left(\mathrm{CaCO}_{3}\right)$ os quais estão associados a baixos batimétricos e aos canais de fundo, locais onde o gradiente ainda é relativamente suave. À medida que atingimos profundidades na faixa entre 25 e 35m e 0 gradiente batimétrico aumenta, há um pequeno aumento relativo nos teores de biodetritos e de finos das ecofácie lamosas. Porém, abaixo de $35 \mathrm{~m}$ de profundidade, no canal central, onde os maiores gradientes batimétricos são observados, a ecofácie presente mostra uma redução relativa no teor de biodetritos.

Evidências da variação de energia local foram observadas com a análise das amostras sedimentológicas de verificação. Estas indicaram ambientes de sedimentação predominantemente de baixa energia, sendo

Tabela 1 - Características das ecofácies da porção centro-leste da baía da llha Grande

Table I - Echo-facies characteristics in the central-eastern portion of Ilha Grande Bay

\begin{tabular}{|c|c|c|c|c|c|c|c|c|c|}
\hline Ecofácies & \begin{tabular}{|l} 
Classificação \\
Textural \\
(Shepard \& \\
Moore, 1954)
\end{tabular} & $\begin{array}{l}\text { 'Classificação de } \\
\text { Sedimentos } \\
\text { Marinhos } \\
\text { (Dias, 1996) }\end{array}$ & $\begin{array}{c}\text { Eco-caráter } \\
\text { perfilador } \\
7.0 \mathrm{kHz}\end{array}$ & $\begin{array}{l}\text { (A) Eco-caráter sonar } \\
\text { (SVL) } 100 \mathrm{kHz}\end{array}$ & $\begin{array}{c}\text { Teor de } \\
\text { biodetritos } \\
\text { carbonáticos } \\
(\%) \\
\end{array}$ & Organismos associados & $\begin{array}{c}\text { Gradiente batimétrico } \\
(\mathrm{m} / \mathrm{m})\end{array}$ & $\begin{array}{l}\text { Ambiente de } \\
\text { Sedimentaçã̃o }\end{array}$ & $\begin{array}{c}\text { Processos } \\
\text { Deposicionais }\end{array}$ \\
\hline I & Lama & $\begin{array}{l}\text { LLlc (lama } \\
\text { terrígena) }\end{array}$ & $\begin{array}{c}\text { Sem penetração ; } \\
\text { sem difusividade } \\
\text { acústica }\end{array}$ & Forte ; heterogêneo & ${ }^{3} 25$ & $N / E$ & $\begin{array}{c}\text { Forte } \\
10\end{array}$ & $\begin{array}{c}\text { Grande depressão do } \\
\text { canal central }\end{array}$ & $\begin{array}{c}\text { Baixa energia ; } \\
\text { contrastes de } \\
\text { densidade }\end{array}$ \\
\hline$\|$ & $\begin{array}{l}\text { Areia média } \\
\text { a grossa }\end{array}$ & $\begin{array}{l}\text { AL2b (areia } \\
\text { litobioclástica } \\
\text { média) }\end{array}$ & $\begin{array}{c}\text { Sem penetração ; } \\
\text { pequena } \\
\text { difusividade } \\
\text { acústica } \\
\end{array}$ & $\begin{array}{l}\text { Grosso heterogêneo } \\
\text { com bolsões de finos }\end{array}$ & $28-90$ & $\begin{array}{c}{ }^{2} \text { Fragmentos de } \\
\text { conchas; foraminíferos }\end{array}$ & $\begin{array}{c}\text { Moderado } \\
2,0-10\end{array}$ & $\begin{array}{l}{ }^{2} \text { Terraços marinhos } \\
\text { atuais e pretéritos }\end{array}$ & $\begin{array}{c}\text { Alta a média } \\
\text { energia ; açõo de } \\
\text { ondas de } \\
\text { tempestade }\end{array}$ \\
\hline III & Areia lamosa & $\begin{array}{c}\text { AL2e (areia } \\
\text { litobioclástica } \\
\text { muito fina) }\end{array}$ & $\begin{array}{c}\text { Pouca penetração ; } \\
\text { grande difusividade } \\
\text { acústica }\end{array}$ & $\begin{array}{l}\text { Médio a fino } \\
\text { heterogêneo }\end{array}$ & $28-48$ & $\begin{array}{c}\text { Poliquetas, equinóides, } \\
\text { gastrópodas, bivalves, } \\
\text { foraminíferos }\end{array}$ & $\begin{array}{l}\text { Suave } \\
0,5-0,05\end{array}$ & $\begin{array}{c}\text { Regiões planas entre } \\
12 \text { e } 18 \mathrm{~m}\end{array}$ & $\begin{array}{c}\text { Alta energia; ação } \\
\text { de ondas refratadas } \\
\text { e difratas }\end{array}$ \\
\hline IV & Lama arenosa & $\begin{array}{l}\text { LLTb (lama } \\
\text { terrígena arenosa) }\end{array}$ & $\begin{array}{c}\text { Pouca penetração ; } \\
\text { muito grande } \\
\text { difusividade } \\
\text { acústica }\end{array}$ & Fino homogêneo & 16 & nenhum & $\begin{array}{c}\text { Suave } \\
0,1\end{array}$ & $\begin{array}{c}\text { Região de inflexão da } \\
\text { paleo drenagem de } \\
\text { fundo }\end{array}$ & $\begin{array}{c}\text { Baixa energia ; } \\
\text { contrastes de } \\
\text { densidade e } \\
\text { vórtices }\end{array}$ \\
\hline V & Lama & $\begin{array}{l}\text { LLlc (lama } \\
\text { terrígena) }\end{array}$ & $\begin{array}{c}\text { Pouca penetração ; } \\
\text { grande difusividade } \\
\text { acústica }\end{array}$ & Fino pouco homogêneo & 19 & nenhum & $\begin{array}{c}\text { Suave } \\
0,1\end{array}$ & $\begin{array}{c}\text { Enseadas abrigadas e } \\
\text { regiões mais rasas } \\
\text { junto a IG }\end{array}$ & $\begin{array}{l}\text { Muito baixa } \\
\text { energia }\end{array}$ \\
\hline VI & Lama & $\begin{array}{l}\text { LL2c (marga } \\
\text { arenosa) }\end{array}$ & $\begin{array}{c}\text { Grande penetração } \\
\text {; difusividade } \\
\text { acústica mediana }\end{array}$ & Fino homogêneo & 32 & $N / E$ & $\begin{array}{c}\text { Moderado } \\
2,2\end{array}$ & $\begin{array}{c}\text { Enseada abrigada junto } \\
\text { ao continente }\end{array}$ & 0 Baixa energia \\
\hline VII & Lama & $\begin{array}{l}\text { LL2c (marga } \\
\text { arenosa) }\end{array}$ & $\begin{array}{c}\text { Grande penetração } \\
\text {; sem difusividade } \\
\text { acústica }\end{array}$ & Fino homogêneo & $31-32$ & $\begin{array}{c}\text { Fragmentos de conchas } \\
\text {; Gastrópodas, } \\
\text { foraminíferos }\end{array}$ & $\begin{array}{c}\text { Moderado } \\
1,0-4,0\end{array}$ & $\begin{array}{c}\text { Regiões entre } 35 \mathrm{e} \\
25 \mathrm{~m} \text { a leste do canal } \\
\text { central }\end{array}$ & $\begin{array}{c}\text { Moderada energia } \\
\text {; correntes de fundo } \\
\text { W-L }\end{array}$ \\
\hline VIII & $\begin{array}{c}\text { Areia média a } \\
\text { grossa }\end{array}$ & $\begin{array}{c}\text { ALld (areia } \\
\text { litoclástica média) }\end{array}$ & \begin{tabular}{|c|} 
Provavelmente sem \\
penetração ; sem \\
difusividade \\
acústica
\end{tabular} & Grosso homogêneo & ${ }^{3}<30$ & $\begin{array}{l}{ }^{2} \text { Moluscose } \\
\text { foraminíferos } \\
\text { limonitizados }\end{array}$ & $\begin{array}{c}\text { Suave a forte } \\
0,008-10\end{array}$ & $\begin{array}{l}\text { Sedimentação relíquia } \\
\text { flúvio marinha }\end{array}$ & $\begin{array}{c}\text { Alta energia; ação } \\
\text { de ondas e } \\
\text { correntes de fundo }\end{array}$ \\
\hline
\end{tabular}

OBS.: (A) indica padróes de reflexão 1 Modificada de Larsonneur et al. (1982) 2 Corrêa et al. (1997) 3 Mahiques (1987) N/E = Nõo Encontrado provavelmente devido a eventos esporádicos de alta energia que devem influenciar a região. Pelotas de lama associadas à fração grossa (observadas à leste do canal), a baixa maturidade mineralógica e a ocorrência de fragmentos de bioclastos retrabalhados, relatados nos trabalhos pioneiros de Mahiques (1987) e Dias e outros (1990), e em Corrêa e outros. (1997), são evidências que sustentam a hipótese de oscilação de energia. As interdigitaççes superficiais das ecofácies lamosas com as arenosas indicam a possibilidade de que as ecofácies III e IV possam ser tipos transitórios entre as ecofácies francamente finas - I, VII e V - e a grossa - VIII - (Figura 6). Formas de fundo foram observadas associadas as ecofácies III e IV. Tais estruturas estão localizadas em profundidades em torno de 16m, próximo a Conceição de Jacareé (Figura 7), onde ocorre uma transição textural de leste para oeste de um padrão de fundo grosso para um padrão fino. Além do controle da topografia submersa no selecionamento dos sedimentos de fundo, a maneira pela qual as disposições dos contatos entre as ecofácies ocorrem sugere um controle hidrodinâmico através da ação de ondas do quadrante SE, e da ação de correntes de fundo resultantes da circulação alguns deles, sujeitos a variações na intensidade dos agentes, 
na baía. Esta disposição dos contatos entre as ecofácies é concordante com os contatos texturais observados por Mahiques (1987) e Dias e outros (1990) nessa região. A Tabela 1 resume as características dos padrões sedimentares observados, associando os respectivos ambientes de sedimentação com os prováveis processos deposicionais envolvidos.

Não é estranho o fato de haver transições de fácies modernas de ambientes estuarinos dominados por agentes de mais alta energia (ondas) para fácies dominadas por agentes de mais baixa energia (maré, correntes de fundo) em ambientes sedimentares de topografia submarina complexa. Pendón e outros (1998) sugere que a simples redução do prisma de maré, relacionado às últimas oscilações do nível médio relativo do mar, favoreceu o preenchimento de paleo-talvegues fluviais pelo surgimento de áreas de mais baixa energia na costa de Huelva, sudeste da Espanha. Na Enseada de Jurujuba, Baía de Guanabara, Baptista Neto e outros. (1996) correlacionando amostras sedimentológicas de fundo com registros de perfilador de subfundo identificou áreas de maior hidrodinamismo, relacionadas à ação de ondas e correntes de maré, e áreas abrigadas, interrompidas por uma zona de transição. Sabe-se que a ação de ondas é um agente hidrodinâmico bastante efetivo, responsável por processos sedimentares de fundo na área costeira bem como na plataforma continental interna. Segundo Mahiques e outros (1998) a interação das direções predominantes de ondas que chegam à área

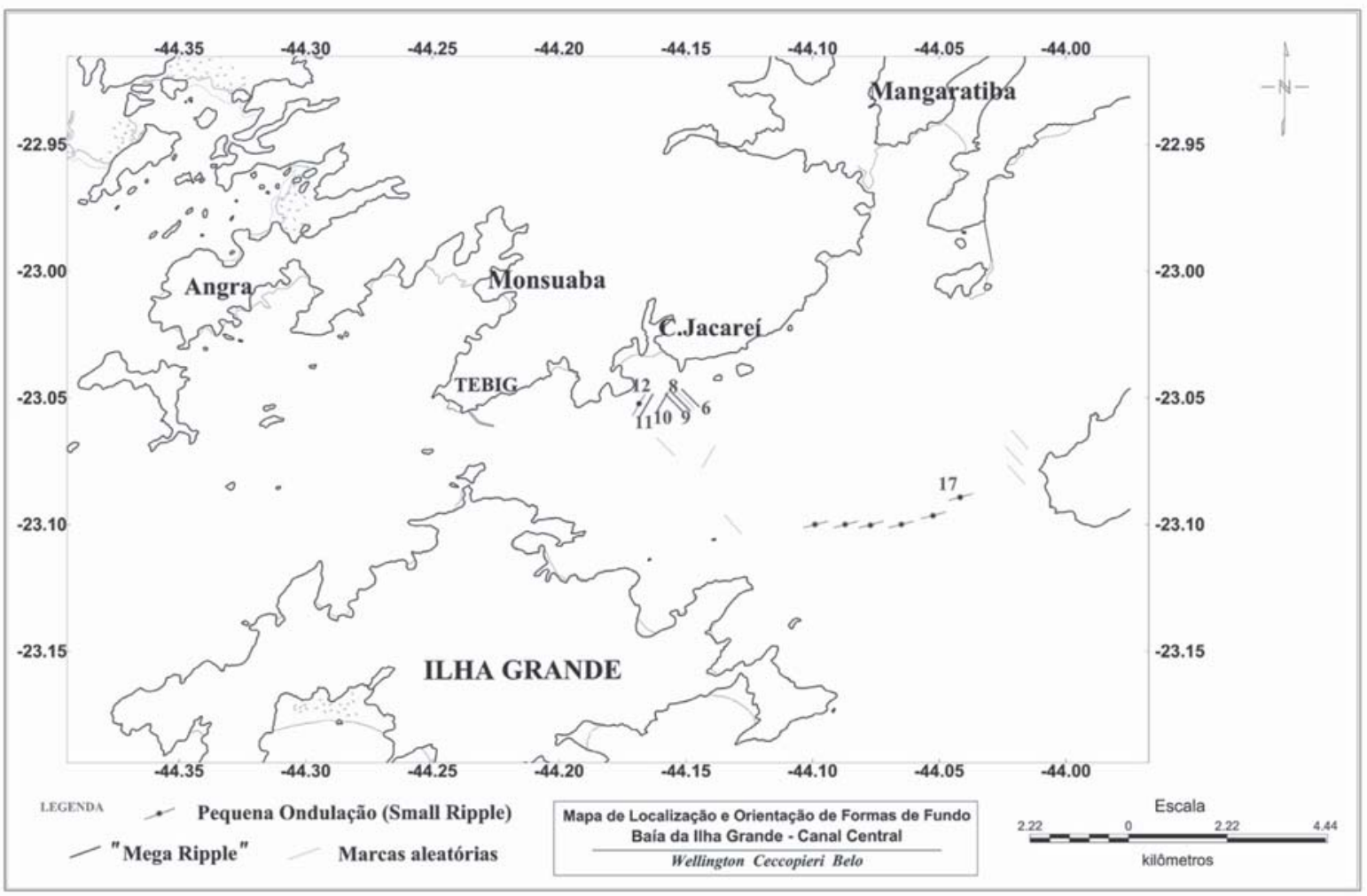

Figura 7 - Localização e orientação das estruturas sedimentares a partir de registros de sonar de varredura lateral (100kHz). Figure 7 - Location and orientation of the sedimentary bedforms observed in side scan sonar (100 kHz) images.

costeira do litoral sudeste brasileiro, preferencialmente de sul e sudeste, com a geometria e orientação da linha de costa, aliada à presença de ilhas, gera sensíveis variações nas características hidrodinâmicas de regiões teoricamente abrigadas como nas enseadas e baías costeiras da região de Ubatuba, ao sul da presente área de estudo.

Furtado (1995), analisando cartas batimétricas, perfis de ecossondagens e análises granulométricas superficiais, associados a parâmetros oceanográficos físicos (marés e ondas), observou uma distribuiç̧ão sedimentar heterogênea associada a áreas de circulação mais intensas e menos intensas do Canal de São Sebastião, ao sul da área de estudo do presente trabalho. Furtado (1995) concluiu que a sedimentação atual é governada pela circulação geral do canal, aliada à sua topografia submersa e à sua geometria, sendo a porção continental com tendências deposicionais e a porção insular com tendências a erosão. Padrão corroborado por Rodrigues e outros. (1999). 
Observou-se ainda na maioria dos registros de 7,0kHz, no presente trabalho, uma unidade sísmica transparente em superfície que parece ser uma lama fluida moderna devido, provavelmente, a uma grande concentração de material particulado em suspensão junto ao fundo. Em tese, esta lama fluida tenderia a ter sua movimentação próxima ao fundo restringida por obstáculos, baixos batimétricos e áreas de menor energia, favorecendo sua deposição. Por outro lado, áreas de maior energia podem ser relacionadas à presença de formas de fundo na região.

Um próximo estudo sobre o fundo marinho da baía da Ilha Grande poderia abordar de maneira simples e objetiva possíveis relações existentes entre as formas de fundo observadas nos registros de sonar $\mathrm{e}$ alguns parâmetros hidrodinâmicos. Este acoplamento coluna d'água sedimento, pode auxiliar, em parte, no entendimento desta configuração dos padrões sedimentares observados no setor centro-leste do canal central.

\section{CONCLUSÃO}

Foram identificados oito padrões sedimentares superficiais de fundo (ecofácies) na região centro-leste do canal central da baía da llha Grande. Estes padrões ocorreram onde o relevo submarino é relativamente complexo. Afloramentos rochosos, canais de fundo, baixos batimétricos, terraços marinhos e regiões de declividade mais suave compõem o fundo marinho. Neste, parece existir uma gradação na energia do escoamento das correntes de fundo e na ação de ondas, de leste para oeste (maior para menor), com reflexos na sedimentação do canal central. Os padrões sedimentares de fundo consistem em transições de um tipo mais grosso, associado a ambientes de sedimentação de maior energia a leste, para tipos mais finos, associados a ambientes de sedimentação de menor energia a oeste, intercalados por tipos transitórios. As feições submarinas, aliadas à presença de formas de fundo e à ação de forçantes hidrodinâmicas, podem contribuir para explicar a distribuição e a ocorrência das ecofácies. A regularidade do relevo submarino mostra, portanto, uma importante relação com o tipo de ambiente de sedimentaçã̃o na baía da llha Grande.

\section{Agradecimentos}

Ao Programa de Recursos Humanos da ANP para o Setor Petróleo e Gás (PRH-ANP/MME/MCT), pelos recursos (Processo no: 48610.002734/99-01 / Matrícula no: 1999.0028-7);

Ao Laboratório de Geologia Marinha (LAGEMAR-UFF) e ao Laboratório de Oceanografia Geológica (LOG-UERJ) pela infra-estrutura, e ao PGGM pelo uso dos equipamentos geofísicos;
À SR2/UERJ por parte dos recursos para os levantamentos geofísicos de maio e dezembro de 1999 e ao Dr. Gilberto Dias pela embarcação (ANITA-RIO);

Ao Dr. Sidney M. Mello (LAGEMAR-UFF), ao Dr. José Antônio Baptista Neto (LAGEMAR-UFF), ao Dr. Cleverson G. Silva (LAGEMARUFF), ao Dr. Michael Mahiques (IOUSP), ao colega Dr. Renato Parkinson (CENPES-PETROBRAS) e à revisão, pelas críticas e sugestões ao manuscrito.

\section{REFERÊNCIAS}

BAPTISTA NETO, J. A.; SILVA, M. A. M.; FIGUEIREDO JR., A. G. Sísmica de alta frequiência e o padrão de distribuição de sedimentos na Enseada de Jurujuba (Baía de Guanabara). Revista Brasileira de Geofísica, Rio de Janeiro, v. 14, p. 51-57, 1996.

BORGELD, J.C. et al. Acoustic backscatter of the 1995 flood deposit on the Eel shelf. Marine Geology, New York, v. 154, p. 197-210, 1999. CORRÊA, I. S. C. et al. Sedimentologia da parte central da Baía da Ilha Grande. Notas Técnicas. Rio de Janeiro: CECO/IG/UFRGS, 1997.

DAMUTH, J.E. Echo character of the western equatorial Atlantic floor and its relationship to the dispersal and distribution of terrigenous sediments. Marine Geology, New York, n. 18, p. 17-45, 1975.

; HAYES, D. E. Echo character of the East Brazilian Continental Margin and and its relationship to sedimentary process. Marine Geology, New York, n. 24, p. M73-M95, 1977.

DIAS, G. T. M.; PEREIRA, M. de A. A.; DIAS, I. de M. Mapa geológico: geomorfológico da Baía da Itha Grande e Zona Costeira adjacente, esc. 1:80000. Universidade Federal Fluminense. Relatório Interno LAGEMAR, 1990.

Classificação de sedimentos marinhos inconsolidados: proposta de representação em cartas sedimentológicas. Congresso Brasileiro de Geologia, 39., 1996, Salvador. Anais... Salvador:SBG, 1996. FISH, J. P.; CARR, H. A. Sound underwater images: a guide to the generation and interpretation of side scan sonar data. Orleans: Lower Cape Pub., 1990.

FLOOD, R. D; SHOR, A. N. Synthetic seismogram generation from sediment composition data: an initial study in the southwest Brazil Basin. Marine Geology, New York, v. 58, p. 263-274, 1984.

FURTADO, V. V. Sedimentação quaternária no Canal de São Sebastião. Instituto Oceanográfico, São Paulo, n. 11, p. 27-35, 1995.

GOFF, J. A. et al. Detailed investigation of continental shelf morphology using a high-resolution swath sonar survey: the Eel margin, northern California. Marine Geology, New York, v. 154, p. 255-269. 1990. 
JUNG, W. Y. et al. Sedimentary structure and origin of a mud-cored pseudo-tidal sand ridge, eastern Yellow Sea, Korea. Marine Geology, New York, v. 151, p. 73-88, 1998.

KALUZA, M. J. et al. Integrating seafloor studies for pipeline routing. Offshore Magazine, North Quincy, v. 59, n. 6, p. 111-134, jun. 1999. LARSONNEUR, C.; BLOUYSSE, P.; AUFFRET, J. P. The surficial sediments of the english channel and its western approaches. Sedimentology, Oxford, v. 29 , n. 6, p. 851-864, 1982.

MAHIQUES, M.M. Considerações sobre os sedimentos de superficie de fundo da Baía da Ilha Grande, Estado do Rio de Janeiro. 2 v. Dissertação (Mestrado)-Instituto Oceanográfico da Universidade de São Paulo, Universidade de São Paulo, São Paulo, 1987.

; TESSLER, M. G.; FURTADO, V. V. Characterization of energy

gradient in enclosed bays of Ubatuba region, south-eastern Brazil. Estuarine, Coastal and ShelfScience, [S.I.], v. 47, n., p. 431-446, 1998. PENDÓN, J. G. et al. Evolution of estuarine facies in a tidal channel environment, SW Spain: evidence for a change from tide- to wavedomination. Marine Geology, New York, v. 147, n., p. 43-62, 1998.
Piaullino, P. 0. V.; Maldonado, P. R.; CAStanõs, G. X. Primeiros resultados do sonar de varredura lateral em águas profundas rebocado próximo ao fundo marinho. In: Congresso Internacional da Sociedade Brasileira de Geofísica, 6. 1999. Rio de Janeiro. Abstracts...Rio de Janeiro: SBGF, 1999.

RODRIGUES, M. et al. Uma revisão histórica acerca do conhecimento sobre a sedimentação atual em ambientes marinhos submersos do Estado de São Paulo. Revista Brasileira de Oceanografia, São Paulo, v. 47, n. 1, p. 91-106, 1999.

SHEPARD, F. P.; MOORE, D. G. Sedimentary environments differentiated by coarse-fraction studies. American Association of Petroleum geologsts, [S.I.], v. 38, p. 1772-1802, 1954.

Sugul0, K. Introdução à sedimentologia. São Paulo: Edgar Blucher, 1973.

\section{NOTAS SOBRE OS AUTORES}

Wellington Ceccopieri Belo é formado em Eletrônica (CEFET-RJ/1988), Graduado em Oceanografia (UERJ/1998), e Mestre em Geologia/Geofísica Marinha (LAGEMAR-UFF-ANP/2001). Tem atuado nas áreas de Oceanografia Geológica e Meteo-Oceanografia. Participou no desenvolvimento de um sistema de monitoramento em tempo real de parâmetros meteo-oceanográficos, junto à CHEMTECH/SIEMENS, para a PETROBRAS. É Oceanógrafo do Centro de Pesquisas da PETROBRAS (CENPES), onde colabora na investigação do clima de vórtices e meandros do Sistema Corrente do Brasil (CB/CCI), junto ao IO-USP, e no desenvolvimento de parâmetros de projeto para unidades de produção marinhas. Seus interesses de pesquisa envolvem dinâmica de sedimentos e instabilidades baroclínicas do escoamento da Corrente do Brasil.

Gilberto T. de M. Dias é Geólogo (UFRJ/1972), Mestre e Doutor em Ciências da Terra (1974/1976) - mention geologie de l'environnement - pela Universidade de Bordeaux I, França. Atualmente é professor adjunto IV do Depto. de Geologia / LAGEMAR-UFF, ministrando na pós-graduação a disciplina Geologia e Geomorfologia Costeira e no curso de especialização as disciplinas aplicadas de Navegação e Posicionamento, Batimetria e Sonar de Varredura Lateral. Participou e coordenou diversas expedições oceanográficas no Brasil e no exterior voltadas ao estudo da sedimentação e estrutura da plataforma continental. Seu interesse de pesquisa envolve o meio ambiente, processos geológicos costeiros, depósitos carbonáticos e recursos minerais marinhos.

Marcelo Sperle Dias é Oceanógrafo (UERJ/1988), Mestre em Geofísica (ON-CNPq/1992) e Doutor em Geofísica (ON-Columbia University/ 1997). Atua nas áreas de Oceanografia Geológica e Geofísica Marinha, sendo Professor Adjunto DE do Instituto de Geociências da UERJ. É responsável por projetos financiados pelo CNPq e FAPERJ, que englobam pesquisas em Exploração de Recursos Minerais e Meio Ambiente. Atualmente é Chefe do Departamento de Oceanografia e Hidrologia da UERJ, Pesquisador da FAPERJ e Consultor AdHoc da FINEP, CNPq, FAPERJ e FACEPE. 